\title{
Influence of L-arginine on Cisplatin-Induced Hepatotoxicity in both normally Fed and Protein Malnourished Rats
}

\author{
Medhat I. Abd-El-Hamid ${ }^{1}$, Azza A. Ali ${ }^{2}$, Hebatalla I. Ahmed ${ }^{2}$, Mohammad M. \\ Abd-Alhaseeb ${ }^{3}$, R. M. El-Sayed ${ }^{3}$ \\ ${ }^{I}$ Department of Pharmacology, Faculty of Medicine, Al -Azhar University, Cairo, Egypt. \\ ${ }^{2}$ Department of Pharmacology and Toxicology, Faculty of Pharmacy, Al-Azhar University, Cairo, Egypt. \\ ${ }^{3}$ Department of Pharmacology and Toxicology, Faculty of Pharmacy, Sinai University, Egypt
}

\begin{abstract}
Liver has great capacity to detoxify toxic substances and synthesized useful principles. Therefore, damage to the liver inflicted by hepatotoxic agents is of grave consequences. Protein malnutrition produces profound effects on biochemistry and physiology of the body as well as growth failure of most body organs. Cisplatin is a member of anticancer drugs that elicits many hepatotoxicity. The study was carried out to investigate the possible hepato-curative and hepato-protective effect of $l$-arginine either alone or in combination with silymarin against hepatotoxicity resulted from cisplatin $(7.5 \mathrm{mg} / \mathrm{kg}$ i.p.) treatment in normally fed and protein malnourished male albino rats. All treatments were administered for 5 consecutive days (l-arginine, 200 $\mathrm{mg} / \mathrm{kg}$ i.p.) and (silymarin, $100 \mathrm{mg} / \mathrm{kg}$ i.p.) after and before cisplatin injection. In the cisplatin group, the results revealed significant decrease in the body weight and increase in alanine aminotransferase and aspartate aminotransferase, as well as liver body weight ratio. Antioxidant status was suppressed as manifested by significant decline in reduced glutathione content and total protein level along with decreased enzymatic activity of super oxide dismutase and increased lipid peroxidation, nitric oxide, an effect that was enhanced by combination with protein malnutrition. Administration of l-arginine was effective in decreasing cisplatin hepatotoxicity that restore of anti-oxidant machinery and blunting of mounted malondialdehyde levels. Moreover, histological examination demonstrated that l-arginine significantly reduced cellular infiltration, congestion blood vessels, degenerative changes in hepatocytes and fatty changes. It is concluded that the combined administration of l-arginine with silymarin represents a promising strategy to restrain the cisplatin hepatotoxicity.
\end{abstract}

Keywords: Antioxidant status, Cisplatin, Hepatotoxicity, L-arginine, Protein malnutrition.

\section{Introduction}

Liver, the key organ in maintenance of homeostasis as well as metabolism and excretion, has an important task of detoxifying xenobiotics and chemotherapeutic agents [1]. Its role in transforming and clearing chemicals renders it susceptible to damage from these agents. Generally, this usually goes unnoticed because of the considerable capacity of hepatocytes to regenerate toxic chemicals and certain drugs has been recognized as a toxicological problem and linked to the occurrence of oxidative stress [2]. Free radical's generation, arising from oxidative stress, is a common mechanism underlying hepatotoxicity caused by deleterious effect of drugs and toxicants. Oxidative stress has also been implicated in the pathogenesis of cellular damage caused by a number of toxic agents including arsenic, diclofenac, carbon tetrachloride (CCl4), cisplatin (CDDP), rifampicin and acetaminophen [3].

Protein malnutrition (PM) has been identified as a major health problem in developing countries [4]. It could be defined as a state of energy, protein or other specific nutrient deficiency which produces measurable changes in body function. It is associated with specific types of illness and is characterized by being reversible by nutritional support [5]. Also, protein malnutrition can occur throughout the lifespan from fetal life through adulthood. As dietary protein is an important source of essential amino acids that can serve as intracellular antioxidant, its restriction may lead to an increase in oxidative damage by diminishing antioxidant defenses of tissue [6]. So that, PM produces profound effects on biochemistry and physiology of the body as well as growth failure of most body organs [7].

Cis-diamminedichloridoplatinum(II) (CDDP, cisplatin) is one of the most effective and widely used chemotherapeutic agents in the treatment of various human solid tumors. Some studies have suggested that hepatotoxicity is also a major dose-limiting side effect of CDDP-based chemotherapy [8,9]. It is widely used for the treatment of several human malignancies, including head and neck cancers [10], testicular cancer [11], small-cell [12] and non-small cell lung cancer [13], ovarian cancer [14]. CDDP has serious side effects, such as ototoxicity, nephrotoxicity and hepatotoxicity $[15,16]$. In spite of its undesirable side effects yet its clinical use depend on its significant anti-cancer effect. Although the mechanism underlying the side effects induced by 
CDDP are not understood clearly, it was considered to be attributed to the combination of multi-ways [17-19], such as the generation of reactive oxygen species (ROS), which could interfere with the antioxidant defense system and result in oxidative damage in different tissues [20-22]. Indeed, other studies have suggested that oxidative stress plays an important role in CDDP-induced liver damage [8,21,22]. Hence, certain amounts of exogenous antioxidants are constantly required to maintain an adequate level of antioxidants in order to balance the ROS in human body.

Silymarin (Sly) is a flavonoid extracted from Silybum marianum (L.). It is also commonly used in herbal therapy especially for treating liver diseases partly due to its antioxidant activity. Silybum marianum has been used for long time in the treatment of liver diseases that caused by drug and chemical oxidative stress [2325].

L-arginine is an essential amino acid that plays pivotal roles in maintaining body homeostasis. It is beneficial in the treatment of hepatic injury, hepatic cirrhosis, fatty liver degeneration [26]. Endothelial nitric oxide synthase (eNOs) produces nitric oxide (NO) from l-arginine. NO can rapidly react with reactive oxygen species to form peroxynitrite which generally relief the oxidative stress (antioxidants) [69]. Although, l-arginine is synthesized in the body, it is not produced in sufficient quantities to support growth or meet metabolic requirements during the periods of PM [27]. Therefore, this study was designed to investigate the possible curative and protective role of 1-arginine on CDDP-induced hepatotoxicity in normally fed (NF) and (PM) rats.

\section{Chemicals and reagents}

\section{Materials And Methods}

Cisplatin: (cisplatyl $50 \mathrm{mg}$, Laboratoire Roger Bellon, France) (CDDP) was purchased from NCI drug store. Silymarin (Sly) was purchased from Sigma-Aldrich Chemical Company (St. Louis, MO, USA). Larginine was purchased by Sigma-Aldrich Chemical Company (St. Louis, MO, USA).

Commercially available kits (Bio-Diagnostic, Egypt) were used for determining superoxide dismutase (SOD) activity and levels of alanine transaminase (ALT), aspartate transaminase (AST), albumin, reduced glutathione (GSH), malondialdehyde (MDA) and nitric oxide (NO). All other chemicals were obtained from Sigma (St. Louis, MO, USA).

\section{Animals}

All animal procedures and experimental protocols were carried out in accordance with the Guide for the Care and Use of Laboratory Animals, Faculty of Pharmacy, Al-Azhar University. The protocol was approved by the committee on the Ethics of Animal Experiments of the Faculty of Pharmacy-University of AlAzhar (Permit Number: 11-2015). The surgery was performed under light ether anesthesia and scarified using cervical dislocation method, and all efforts were made to minimize suffering. Male albino rats weighting 100$120 \mathrm{~g}$ were obtained from the Egyptian Organization for Biological Products and Vaccines (Vacsera, Egypt) and housed under controlled temperature $\left(25 \pm 1^{\circ} \mathrm{C}\right)$ on a $12 \mathrm{~h} \mathrm{light/dark} \mathrm{cycle.} \mathrm{Food} \mathrm{and} \mathrm{water} \mathrm{were} \mathrm{allowed} \mathrm{and} \mathrm{ad}$ libitum during the study period. Two weeks prior to drug administration, rats were fed two types of diets were utilized depending on the amount of casein: Normal protein diet containing 20\% casein [28] or low protein diet containing $8 \%$ casein [29]. Each $1000 \mathrm{~g}$ of the standard protein diet contained casein $(200 \mathrm{~g})$, a mixture of sucrose and starch $(700 \mathrm{~g})$, a salt mixture $(40 \mathrm{~g})$, oil and oil-soluble vitamins $(250 \mathrm{~g})$, a vitamin mixture in starch $(6 \mathrm{~g})$ and a choline-starch mixture 1:3 (4g). The low-protein diet contained the same constituents of the low protein diet with the exception of the amount of casein, which was $50 \mathrm{~g}$ per $1000 \mathrm{~g}$; the difference in weight $(150 \mathrm{~g})$ was replaced by a sucrose-starch mixture.

\section{Pharmacological treatment}

One hundred and twenty eight adult male albino rats adult male albino rats were randomly divided into two sets: (set I) normally fed (NF) and protein malnourished (PM) rats (set II) sets. Each set was divided into eight groups of eight rats each, as follows: (1) Control group: rats were injected intraperitoneal (i.p.) with isotonic saline solution (vehicle of CDDP), (2) CDDP group: rats were administered single dose of CDDP (7.5 $\mathrm{mg} / \mathrm{kg}$ i.p.), [30] on the 1st day, (3) Sly group (curative): rats were administered single dose of CDDP (7.5 mg/ $\mathrm{kg}$ ip) on the 1 st day and administered Sly at a dose (100 mg/ kg i.p.), [31], for 5 consecutive days, (4) Larginine group (curative) : rats were administered single dose of CDDP (7.5 mg/ kg i.p.) on the 1st day and administered 1-arginine (200mg/ kg i.p.) [26], for 5 consecutive days. (5) Co-administered Sly with 1-arginine group (curative): rats were administered single dose of CDDP (7.5 mg/ kg i.p.) on the 1st day and coadministered Sly with 1-arginine with the same previously mentioned regimen, (6) Sly group (protective): rats were administered Sly at a dose (100mg/ kg i.p.) for 5 consecutive days and administered single dose of CDDP $(7.5 \mathrm{mg} / \mathrm{kg}$ i.p.) on the 5th day, (7) L-arginine group (protective): rats were administered l-arginine at a dose (200mg/ kg i.p.) for 5 consecutive days and administered single dose of CDDP ( $7.5 \mathrm{mg} / \mathrm{kg}$ i.p.) on the 5 th day, 
(8) Co-administered Sly with 1-arginine group (protective): rats were administered Sly with 1-arginine with the same previously mentioned regimen and administered single dose of CDDP $(7.5 \mathrm{mg} / \mathrm{kg}$ i.p. $)$ on the 5 th day.

On 6th day in the control group and on day 6 after CDDP administered, curative and protective group, the animals were reweighted and scarified for the evaluation of all parameters.

\section{Sample collection}

Blood samples were collected on EDTA (for plasma) or without EDTA (for serum) through the orbital sinus, under light ether anesthesia, centrifuged at $1000 \mathrm{X} \mathrm{g}$ for $15 \mathrm{~min}$. Serum, plasma and erythrocyte lysate samples were separated and stored at $-80^{\circ} \mathrm{C}$. After scarification and the liver was removed, washed thoroughly with ice-cold saline $(0.9 \%$ sodium chloride) and weighed. A piece of the right lobe of the liver of each animal was frozen and stored at $-80^{\circ} \mathrm{C}$, whereas the rest of the organ was maintained in $10 \%$ formalin for histopathological studies.

\section{Weight measurement}

The animal's weights were measured at the final day before scarification.

\section{Liver ratio (relative liver weight to body weight)}

Liver was removed and weight immediately. Liver ratio was calculated as the following formula, liver ratio was calculated as the following formula, organ ratio $(\%)=$ organ weight $(\mathrm{g}) \times 100 /$ body weight $(\mathrm{g})$.

\section{Alanine aminotransferase (ALT) and aspartate aminotransferase (AST)levels in serum}

ALT and AST levels were estimated according to the method of Reitman and Frankel [32]. Colorimetric determination of ALT or AST was estimated by measuring the amount of pyruvate or oxaloacetate produced by forming 2, 4-dinitrophenylhydrazine. The color of which was measured at $520 \mathrm{~nm}$ using colorimeter (6051 JENWAY designed and manufactured in the EU by Bar lowered scientific Ltd. Dunmow. Essex CM63LB, model 6051, voltage 230/115V, frequency 50/60 Hz and power 20VA).

\section{Albumin level in serum}

Albumin level was measured according to the method of [33].

\section{Lipid per-oxidation level in serum}

Lipid per-oxidation was a good way for evaluating oxidative stress-induced damage to tissues. Hence levels of malondialdehyde as thiobarbituric acid-reactive substances were measured in serum by the method of [34]. Briefly, thiobarbituric acid reacts with malondialdehyde in acidic medium at temperature of $95^{\circ} \mathrm{C}$ for 30 min to form colored substances. The resultant pink color representative of thiobarbituric acid-reactive substances was measured at $534 \mathrm{~nm}$ using colorimeter (6051 JENWAY designed and manufactured in the EU by Bar lowered scientific Ltd. Dunmow. Essex CM63LB, model 6051, voltage 230/115V, frequency 50/60 Hz and power 20VA).

\section{Superoxide-dismutase activity in erythrocyte lysate}

Erythrcyte lysate was prepared from different samples according to standard protocol [35]. Activity of the antioxidant enzyme superoxide-dismutase was measured in the erythrocyte lysate using standard spectrophotometric assay. Briefly, Superoxide-dismutase activity in the erythrocyte lysate was determined by generating superoxide radicals by the photochemical reduction of phenazine methosulphate, which reduced nitro blue tetrazolium into a blue-colored compound, formazone. Superoxide-dismutase quenches free oxygen radicals and inhibited reduction of nitrobluetetrazolium, which was measured at $560 \mathrm{~nm}$ using colorimeter $(6051$ JENWAY designed and manufactured in the EU by Bar lowered scientific Ltd. Dunmow. Essex CM63LB, model 6051 , voltage $230 / 115 \mathrm{~V}$, frequency $50 / 60 \mathrm{~Hz}$ and power 20VA) [36].

\section{Reduced glutathione in liver tissue}

Glutathione is a key antioxidant and is used as an indicator of the reduction capacity of the tissue. Glutathione was determined by the spectrophotometric method, which was based on the use of Ellman's reagent. Results were expressed in micromoles of glutathione per gram tissue [37].

\section{Determination of tissue nitric oxide}

Nitrite concentration was measured in tissue samples as indicator of nitric oxide production using Griess reaction. Briefly, in acid medium and in the presence of nitrite, the formed nitrous acid diazotizes sulphanilamide and the product was coupled with $\mathrm{N}$-(1-naphthyl) ethylenediamine. The resulting purple azo dye was measured at $540 \mathrm{~nm}$. 


\section{Histo-pathological examination}

Liver samples were collected, rinsed in $10 \%$ formalin, dehydrated, cleared, impregnated, blocked and embedded in paraffin according to standard histological techniques. Six-micrometre-thick sections were cut through the liver. The sections were stained with hematoxylin and eosin (H\&E) for light microscopic examination [38].

\section{Statistical analysis}

The quantitative data of continuous variables were expressed as mean \pm S.E.M. Statistical significance was tested by one way analysis of variance (ANOVA) followed by Bonferroni post hoc test. All statistical tests were performed using the Statistical Package for Social Sciences, version 19 (SPSS Software, SPSS Inc., Chicago, USA), and the differences were considered significant when $P \leq 0.05$.

\section{Effect on body weight}

\section{Results}

The protein-malnourished rats showed a significant decrease in body weight compared with NF rats. In addition, body weights were compared among all groups on day 5- post CDDP administration $(7.5 \mathrm{mg} / \mathrm{kg})$. Current results showed that administration a single dose of CDDP caused a significant decrease in body weight by $6.6 \%$ in the NF rats and $7.6 \%$ in the PM rats when compared to corresponding control group. In contrast, administration of Sly, l-arginine and their combination for 5 days after CDDP administration significantly increased the body weight by $8.56 \%, 4.6 \%$ and $7.8 \%$ in the NF rats and by $6.6 \%, 6.2 \%$ and $8 \%$ in the PM rats, respectively, compared with administration of CDDP alone. Administration of Sly, 1-arginine and their combination for 5 days and prior CDDP administration significantly increased the body weight by $8.5 \%, 8.84$ and 7.26 in the NF rats and by $10.4 \%, 11.5 \%$ and 14.24 in the PM rats, respectively, compared with administration of CDDP alone $(P \leq 0.05)$ (Table 1$)$.

\section{Effect on liver ratio (relative liver weight to body weight)}

The protein-malnourished rats showed a significant decrease in relative liver weight compared with the NF rats. Comparing liver ratio on day 5 post intra peritoneal injection of CDDP successfully induced liver toxicity as was evident by a significant increase $(\mathrm{P} \leq 0.05)$ in liver ratio by $57.5 \%$ in the NF rats and $80 \%$ in the $\mathrm{PM}$ rats compared with corresponding control group. Administration of Sly, 1-arginine and their combination for 5 days after CDDP significantly decreased the liver ratio by $35.3 \%, 38.7 \%$ and $43.6 \%$ in the NF rats and by $44.7 \%, 41.5 \%$ and $40.1 \%$ in the PM rats, respectively, compared with administration of CDDP alone. Also, administration of Sly, 1-arginine and their combination for 5 days and prior CDDP administration significantly decreased the liver ratio by $36.4 \%, 36.4 \%$ and $35.4 \%$ in the NF rats and by $35.14 \%, 37.2 \%$ and $44.1 \%$ in the $\mathrm{PM}$ rats, respectively, compared with administration of CDDP alone $(P \leq 0.05)$ (Table 2$)$.

\section{Effect on serum ALT and AST level}

Serum ALT and AST levels were determined on days 5 after administration CDDP that induced hepatotoxicity. The CDDP-treated alone group showed a significant increase $(P \leq 0.05)$ in ALT and AST enzyme activity by $(\approx 1$ fold), in the NF and the PM rats, compared with corresponding control group. Administration of Sly, 1-arginine and their combination for 5 days after CDDP significantly decreased in ALT serum levels by $42.1 \%, 38.4 \%, 46.3 \%$ and AST by $44.4 \%, 39.9 \%, 42.5 \%$ Also, their administration for 5 days before CDDP showed significantly decreased in ALT serum levels by 37.3\%, 37.5\%, 39.5\% and AST by 39.8\%, $42.5,45.1 \%$ in the NF rats, respectively, compared with administration of CDDP alone. Interestingly, a regression in ALT and AST serum levels was observed in curative and protective regimen in the PM rats, yet remained higher than normal level (Fig. 1, 2).

\section{Determination of serum albumin level}

The administration of CDDP $(7.5 \mathrm{mg} / \mathrm{kg})$ resulted in a significant decrease of serum albumin level by $54.7 \%$ in the NF rats and by $61.3 \%$ in the PM rats, respectively, compared to corresponding control group. Individual treatment and the individual pretreatment with Sly, 1-arginine and their combination significantly partially increased the serum albumin level by $49.1 \%, 60.8 \%, 85.4 \%, 55.3 \%, 86.5 \%$ and $111.7 \%$ in the NF rats and by $90.9 \%, 100 \%, 152.5 \%, 72.7 \%, 92.9 \%$ and $100 \%$ in PM rats compared to CDDP treated alone. Individual pretreatment with 1-arginine, its combination with Sly in curative and protective group successfully normalized albumin level in the NF rats. Furthermore, the combination of 1-arginine with Sly in curative group successfully normalized albumin level in the PM rats (Fig. 3).

\section{Effect on lipid per-oxidation}


To study the differential and the combined effect of Sly and 1-arginine on lipid peroxidation induced by CDDP in the NF rats and PM rats, serum MDA levels were evaluated in different treatment groups. A significant $(\mathrm{P} \leq 0.05)$ increase in serum MDA levels were observed in CDDP-treated alone group in the NF rats and $\mathrm{PM}$ rats, compared to corresponding control group. The individual treatment as curative and protective with Sly, l-arginine or their combination blunted the mounted levels of MDA by $31.6 \%, 33.2 \%, 40.9 \%, 30.2 \%, 43.6$ and $40.4 \%$ in the NF rats and by $23.8 \%, 31.75 \%, 36.5,25.8 \%, 30.2 \%$ and $32.1 \%$ in the PM rats indicating a partial protection against lipid peroxidation in all treated groups (Fig. 4).

\section{Effect on superoxide-dismutase}

On the other hand, the activity of the anti-oxidant enzyme SOD significantly decreased in the erythrocytes lysate of CDDP treated-alone in NF and PM rats $(\mathrm{P} \leq 0.05)$ when compared to corresponding control group, indicating attenuation of anti-oxidative defense. The treatment with Sly, 1-arginine, their combination after CDDP administration and the pretreatment with the same regimen prior to CDDP administration resulted in a significant increase in SOD by $30.9 \%, 28.3 \%, 49.7 \%, 45.8 \%, 39.9 \%$ and $46.3 \%$ in the NF rats and by $69.4 \%, 65.2 \%, 84.8 \%, 68 \%, 72.6 \%$ and $86.6 \%$ in the PM rats, respectively when compared to CDDP treated alone (Fig. 5).

\section{Effect on reduced glutathione}

Parallel to SOD activity, GSH level was found to be significantly $(\mathrm{P} \leq 0.05)$ deceased in the tissue sample of CDDP-treated alone rats when compared to corresponding control group. Individual treatment and pretreatment with Sly, l-arginine and their combination significantly up-regulated GSH levels by $64.3 \%, 43 \%$, $74.2 \%, 58.8 \%, 53.6 \%$ and $69 \%$ in the NF rats and by $64.4 \%, 85.2 \%, 95.7 \%, 95.7 \%, 76.6 \%, 74.8 \%$ and $80.9 \%$ in the PM rats, respectively, compared with administration CDDP alone (Fig. 6).

\section{Effect on tissue nitrite concentration}

An effect of CDDP was observed on oxidative stress parameters. CDDP significantly elevated tissue nitrite concentration level in the NF rats and PM rats. The treatment with Sly, 1-arginine and their combination for 5 consecutive days after and before CDDP administration resulted in a significant decreased in nitrite concentration by approximately $75.3 \%, 34.55,64.4 \%, 69.2 \%, 52.4 \%$ and $66.6 \%$ in the NF rats and by $55.6 \%$, $35.8 \%, 48.5 \%, 54.2 \%, 37.8 \%$ and $49.6 \%$ in the PM rats, respectively, compared with administration of CDDP alone. Interestingly, the curative and the protective effect of 1-arginine revealed minimum regression in nitrite concentration yet remained higher than normal level in the NF rats and PM rats (Fig. 7).

\section{Histopathological examination}

Histopathological examination revealed a normal liver histology in the control group (Fig. 8 a), in the NF rats but showed fatty changes in the hepatocytes of the control group (Fig. 9 a), in the PM rats. But in the histo-pathological examination of the liver tissue on day 6 after CDDP injection revealed severe mononuclear cellular infiltration around the congested blood vessels and different degenerative changes in hepatocytes and loss of hepatocytes (Fig. 8 b), in the NF rats and the liver of CDDP treated group rat of the PM set showed sever mononuclear cellular infiltration around the congested blood vessels and band of fibrous tissue scattered fatty changes in the hepatocytes, (Fig. 9 b).

In addition, the individual treatment as curative and protective with Sly reduced mononuclear cellular infiltration, congestion blood vessels, degenerative changes in hepatocytes and fatty changes to less extent than the treatment with CDDP alone in the NF and PM rats, (Fig. 8 c, 8f; Fig. 9 c, 9 f) respectively.

Interestingly, liver sections of rats in the groups of individual treatment and pretreatment with 1arginine after CDDP administration showed that reduction mononuclear cellular infiltration, congestion blood vessels, degenerative changes in hepatocytes and fatty changes to lesser extent than the treatment with CDDP alone but showed marked dilatation in the sinusoids in the NF and PM rats, (Fig. 8 d, 8 g; Fig. 9 d, 9 g) respectively.

Furthermore, the combination treatment as curative and protective with 1-arginine and Sly after CDDP administration showed nearly the same histological profiles as in the control group with marked sinusoidal dilation in the NF and PM rats, (Fig. 8 e, 8 h; Fig. 9 e, 9 h), respectively.

\section{Discussion}

Nutritional stress in the form of deficient protein condition is quite prevalent in developing countries [39]. Protein-deficient diet intake has been shown to influence the activity of drug metabolizing enzymes as well as antioxidant enzymes [40].

In this study, a model of protein malnutrition (PM) was successfully established by feeding rats a low protein diet $(5 \%)$ according to the study of $[41,42]$ where the PM rats showed a significant decrease in relative 
liver weight compared to NF rats. These results are in agreement with Bozzetti study. who reported that the growth rate during PM was significantly lower than that during normal conditions [43]. The decrease in body weight observed in the PM rats may be due to a reduction in the levels of protein and food consumption [44]. Moreover, the present study revealed that the PM rats showed a significant increase in serum ALT and AST levels compared to the NF rats. These results supported by the study of Obima [45]. The elevation in serum AST and ALT levels due to PM may be caused by up regulation of the tumor necrosis factor (TNF) in the serum and of the absolute amounts of TNF secreted by cells, leading to an increase in the rate of cell damage as a consequence of PM [46]. This study showed that a significant increase in serum MDA and reduction in SOD, GSH and albumin levels were observed in the PM rats compared to the NF rats. These findings are in accordance with those of the studies of $[47,48]$. These findings suggest an altered protein and antioxidant status in protein-energy malnutrition.

Cisplatin can induce hepatotoxicity after having administered at high doses [49,50]. To better understand the mechanism by which CDDP succeeded in the induction of hepatotoxicity, we analyzed serum levels liver enzymes and oxidative stress markers.

In the present study, CDDP-treated NF and PM rats induced liver impairment was evidenced by an increase in serum ALT, AST, MDA and tissue nitrite concentrations level and in relative liver weight accompanied with significant decrease in serum albumin levels, GSH and SOD levels compared to corresponding control group. These results are in agreement with the study reported by Naqshbandi et al [51]. This observation is consistent with a recent report by Yadav, (2015) that showed CDDP administration induced significant increase in serum ALT, AST and significant decrease in serum total protein, and albumin levels [30]. The ability of CDDP to cause alterations in the activity of these enzymes could be a secondary event following CDDP-induced liver damage with the consequent leakage from hepatocytes. It has been shown previously that oxidative stress due to the formation of free radicals is one of the pathogenic mechanisms underlying the adverse effects of CDDP in the liver [56]. Oxidative stress can occur as a result of an increase in ROS generation and/or a decrease in the antioxidant enzyme system. These antioxidant enzymes protect the cell against cytotoxic ROS. Moreover, depletion of GSH may contribute to CDDP-induced lipid peroxidation. Thus, an alteration in the enzymatic antioxidant status accompanied by an increase in lipid peroxidation and tissue nitrite concentrations level indicates that the enzymes play an important role in combating free radical-induced oxidative stress in tissues [58].

L-arginine is an essential amino acid that has numerous functions in the body and plays an important role in cell division, healing of wounds and in immune function [59,60]. Results of the present study showed that the weight loss by CDDP could be improved by l-arginine treatment in the NF and PM rats. In harmony with our results, Saleh \& El-Demerdash, (2005) reported that l-arginine ameliorates weight loss induced by CDDP in male rats. Also, 1-arginine may diminish the weight loss induced by obstructive jaundice in male rat and the increased in the body weight was attributed to modulation of immune function [61], an effect that was enhanced by combination with Sly. In the current study, Sly, 1-arginine and their combination-treated rats exhibited a significantly increased hepatic antioxidant activity (SOD and GSH levels), serum albumin levels compared to CDDP group in the NF and PM rats. Moreover, the serum indices of hepatotoxicity (ALT, AST), and lipid peroxidation level were significantly decreased compared to CDDP group in the NF rats and PM rats. In the line with our results Moustafa \& Badria, (2010) who reported that l-arginine was significantly decreased serum levels of ALT, AST, lipid peroxidation and OH radicals when compared to hepatotoxic group, due to their antioxidant effect and their ability to act as a free radical scavenger and showed that severe decrease in albumin by CDDP injection tended to be normalized by the effect of 1 -arginine. It has been shown previously that 1 -arginine treatment have anti-oxidant effect in carbon tetrachloride-induced (CCl4) hepatic injury in mice [62].The current work was supported by the results of [26], in which 1-arginine can ameliorate the kidney dysfunction and that was related to the improvement of the functional status of the liver . In addition to, 1arginine administration resulted in reversed alterations in antioxidant defense system components in liver from rats with low resistance to hypoxia [63].

Interestingly, although 1-arginine is an NO donor, It was showed a significant decreased in nitrite concentration compared to CDDP treated group in the NF and PM rats that it is attributed to NO inhibits inducible nitric oxide synthase (iNOS) own gene expression, at the level of transcription, by down-regulating NF-KB expression in rat hepatocytes and primary human hepatocyte iNOS mRNA, protein, and NO release were markedly suppressed in the presence of either endogenously produced NO or an NO donor as levels of NO increase, feedback regulation begins and NO negatively modulates NF-KB DNA binding activity and enzyme activity to tightly regulate the amount of NO produced. This data identifies a novel negative feedback loop whereby NO down-regulates iNOS gene expression possibly to limit over production during pathophysiologic conditions [68]. This would explain why l-arginine revealed minimum regression in nitrite concentration yet remained higher than normal level in the NF rats and PM rats. 
Some researches about the role of NO in the regulation of hepatic microcirculation have shown that the 1-arginine-derived iNOS activation supports vasodilatation and inhibition of platelet functions [64,65].

The effect of Sly is consistent with a recent report by Ezzeldin et al., (2014) who reported that Sly increased the activities of antioxidant enzymes, albeit to different extents, when accompanied by CDDP administration. These results indicate a marked protection afforded by natural products against CDDP-induced oxidative damage to liver tissues. Furthermore, Sly has the ability to scavenge free radicals and ROS and of strengthening the antioxidant system [66]. These results were also in agreement with those of study of [67], who reported that the protective action of Sly is associated with its anti-oxidant properties.

According to pathological finding in this study the combination of Sly and 1-arginine further significant reduction in the total histo-pathological changes and was confirmed by normalization of all previously mentioned changes and resuming normal histological architecture with sinusoidal dilatation in the NF and PM rats, respectively. These marked sinusoidal dilatation due to NO vasodilatation effect [68] indicating the enhancing effect of 1-arginine on anti-hepato-toxicity activities of Sly. In harmony with our results, Nahavandi et al. was found that histo-pathological changes were partially but significantly prevented by exogenous 1arginine in obstructive jaundiced rats where 1-arginine played a protective role by inducing iNOS expression and NO synthesis [69].

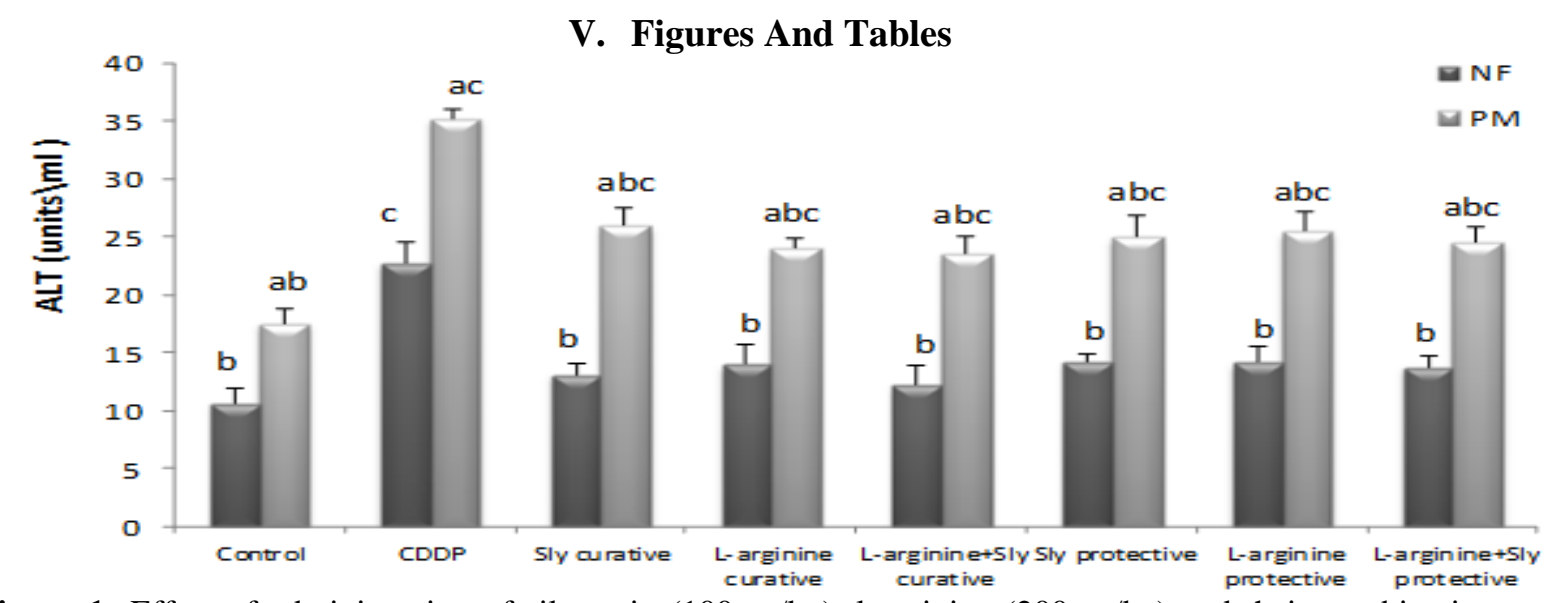

Figure 1: Effect of administration of silymarin $(100 \mathrm{mg} / \mathrm{kg}), 1$-arginine $(200 \mathrm{mg} / \mathrm{kg})$ and their combination on ALT enzyme activity in cisplatin-induced liver toxicity in normally fed and in protein malnourished rats. ALT serum levels of rats were measured and expressed as mean \pm S.E.M. All data were analyzed using ANOVA followed by Bonferroni post hock test. a $\mathrm{P} \leq 0.05$ with respect to corresponding normally fed group, $\mathrm{b} \mathrm{P} \leq 0.05$ with respect to corresponding cisplatin treated group, c $\mathrm{P} \leq 0.05$ with respect to corresponding control group.

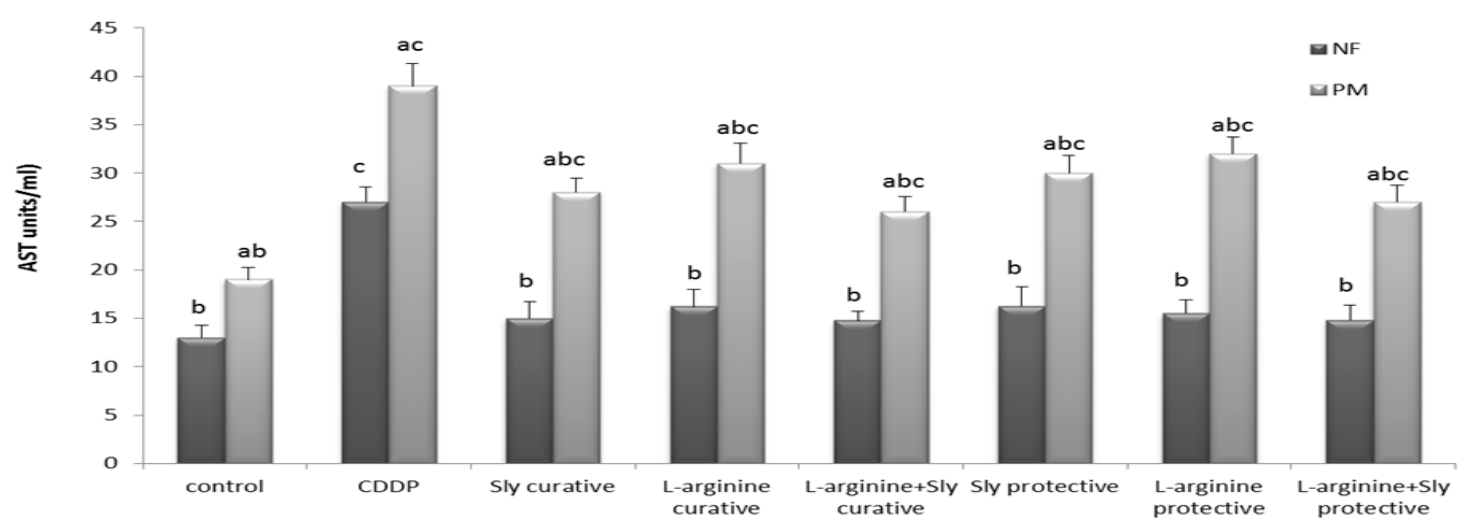

Figure 2: Effect of administration of silymarin $(100 \mathrm{mg} / \mathrm{kg}), 1$-arginine $(200 \mathrm{mg} / \mathrm{kg})$ and their combination on AST enzyme activity in cisplatin-induced liver toxicity in normally fed and in protein malnourished rats. AST serum levels of rats were measured and expressed as mean \pm S.E.M. All data were analyzed using ANOVA followed by Bonferroni post hock test. a $\mathrm{P} \leq 0.05$ with respect to corresponding normally fed group, b $\mathrm{P} \leq 0.05$ with respect to corresponding cisplatin treated group, c $\mathrm{P} \leq 0.05$ with respect to corresponding control group. 


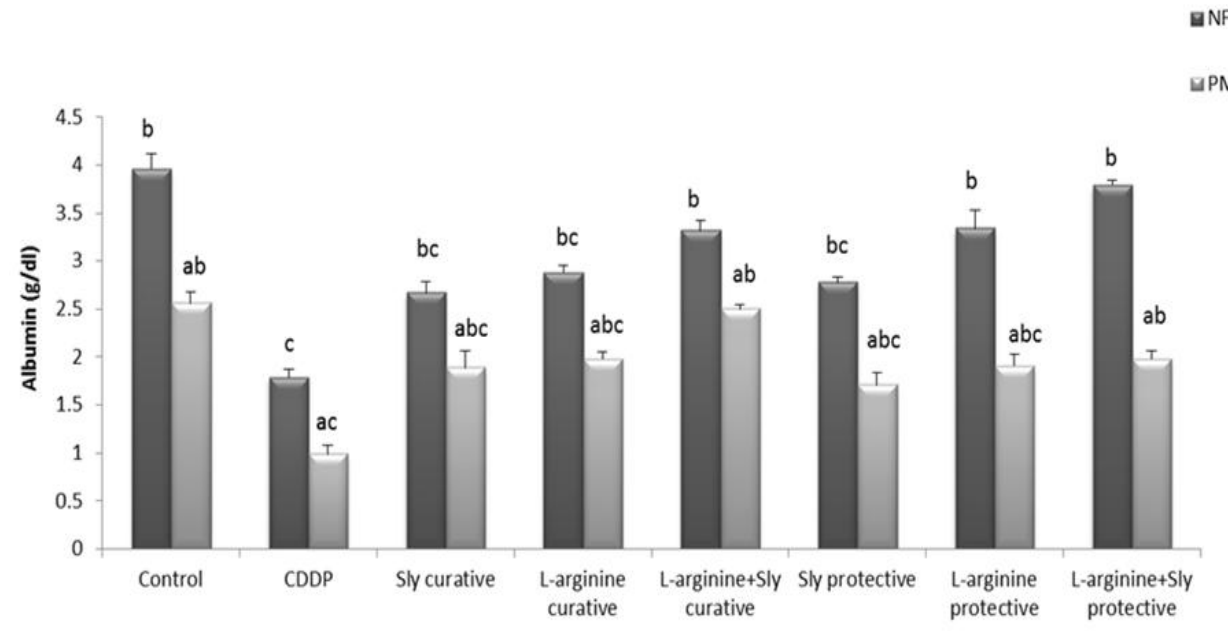

Figure 3: Effect of administration of silymarin $(100 \mathrm{mg} / \mathrm{kg}), 1-\operatorname{arginine}(200 \mathrm{mg} / \mathrm{kg})$ and their combination on the albumin levels in cisplatin-induced liver toxicity in normally fed and in protein malnourished rats were evaluated spectrophotometrically. Values are expressed as mean \pm S.E.M. All data were analyzed using ANOVA followed by Bonferroni post hock test. a $\mathrm{P} \leq 0.05$ with respect to corresponding normally fed group, $\mathrm{b}$ $\mathrm{P} \leq 0.05$ with respect to corresponding cisplatin treated group, c $\mathrm{P} \leq 0.05$ with respect to corresponding control group $(\mathrm{n}=8)$.

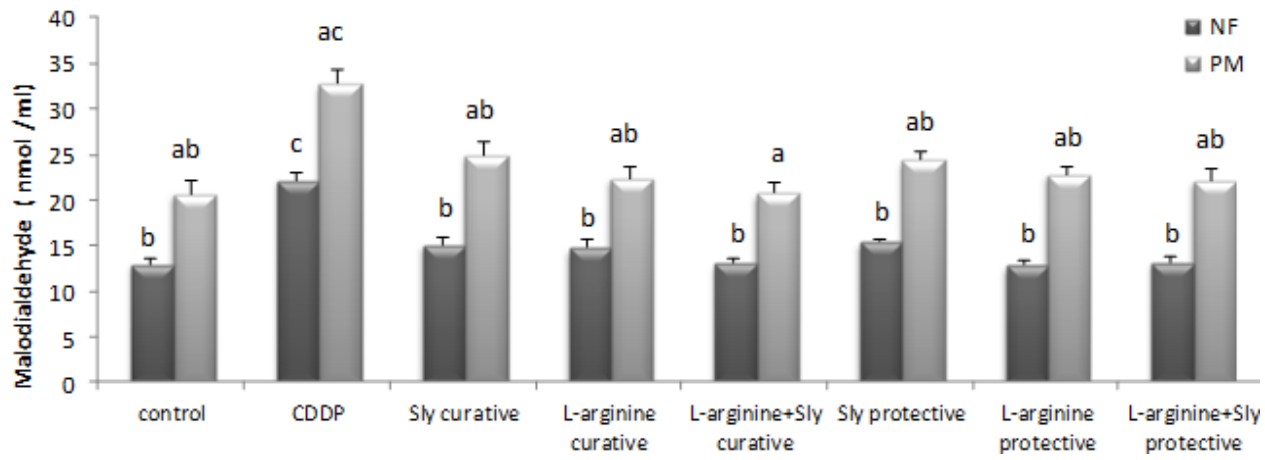

Figure 4: Effect of administration of silymarin $(100 \mathrm{mg} / \mathrm{kg}), 1-\operatorname{arginine}(200 \mathrm{mg} / \mathrm{kg})$ and their combination on lipid peroxidation in cisplatin-induced liver toxicity in normally fed and in protein malnourished rats. Serum levels of malondialdehyde as thiobarbituric acid-reactive substances were measured spectrophotometrically and expressed as mean \pm S.E.M. All data were analyzed using ANOVA followed by Bonferroni post hock test. a $\mathrm{P} \leq 0.05$ with respect to corresponding normally fed group, $\mathrm{b} \mathrm{P} \leq 0.05$ with respect to corresponding cisplatin treated group, $\mathrm{c} P \leq 0.05$ with respect to corresponding control group ( $\mathrm{n}=8)$.

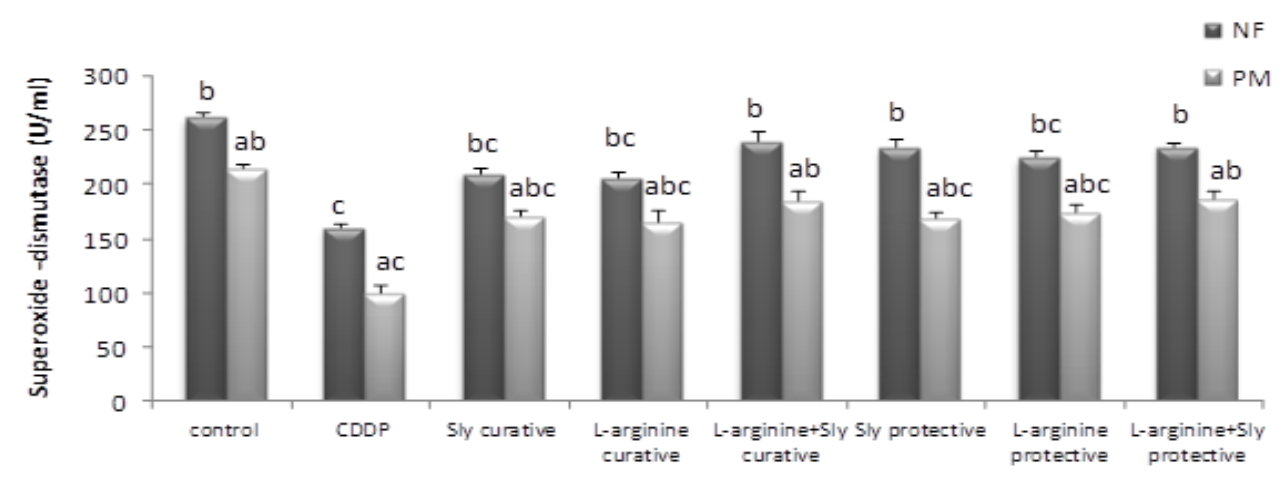

Figure 5: Effect of administration of silymarin $(100 \mathrm{mg} / \mathrm{kg}), 1-\operatorname{arginine}(200 \mathrm{mg} / \mathrm{kg})$ and their combination on the evaluation of enzymatic antioxidant (superoxide-dismutase) in cisplatin-induced liver toxicity in normally fed and in protein malnourished rats were evaluated spectrophotometrically and expressed as mean \pm S.E.M. All data were analyzed using ANOVA followed by Bonferroni post hock test. a $\mathrm{P} \leq 0.05$ with respect to corresponding normally fed group, b $\mathrm{P} \leq 0.05$ with respect to corresponding cisplatin treated group, c $\mathrm{P} \leq 0.05$ with respect to corresponding control group $(\mathrm{n}=8)$. 


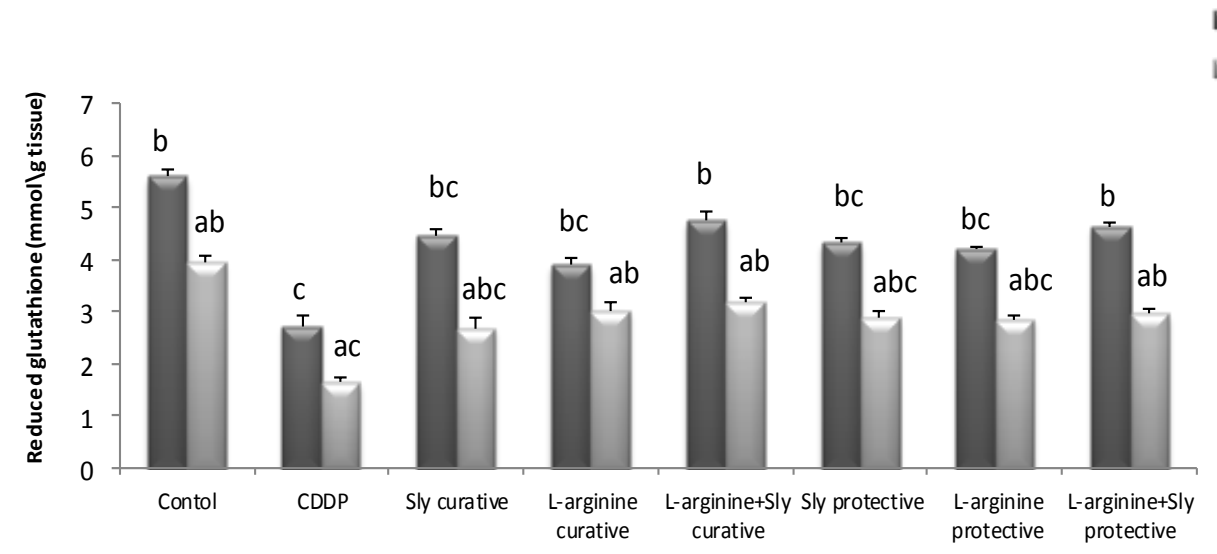

Figure 6: Effect of administration of silymarin $(100 \mathrm{mg} / \mathrm{kg}), 1$-arginine $(200 \mathrm{mg} / \mathrm{kg})$ and their combination on the evaluation of non-enzymatic antioxidants (reduced glutathione) in cisplatin-induced liver toxicity in normally fed and in protein malnourished rats were evaluated spectrophotometrically. Values are expressed as mean \pm S.E.M. All data were analyzed using ANOVA followed by Bonferroni post hock test. a $\mathrm{P} \leq 0.05$ with respect to corresponding normally fed group, $\mathrm{b} P \leq 0.05$ with respect to corresponding cisplatin treated group, $\mathrm{c} P \leq 0.05$ with respect to corresponding control group $(n=8)$.

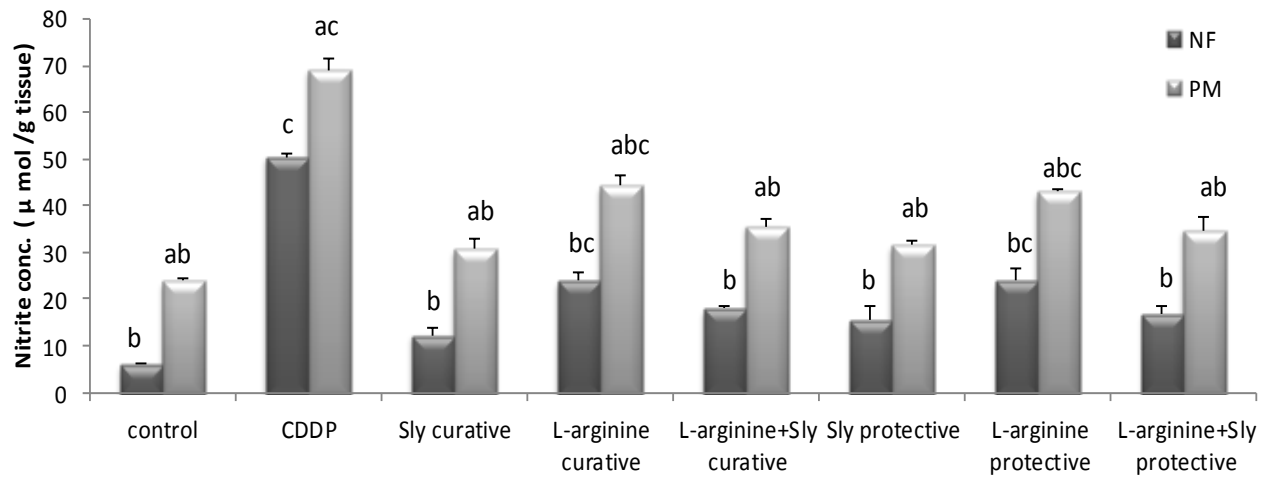

Figure 7: Effect of administration of silymarin $(100 \mathrm{mg} / \mathrm{kg}), 1$-arginine $(200 \mathrm{mg} / \mathrm{kg})$ and their combination on the nitrite concentrations in cisplatin-induced liver toxicity in normally fed and in protein malnourished rats were evaluated spectrophotometrically. Values are expressed as mean \pm S.E.M. All data were analyzed using ANOVA followed by Bonferroni post hock test. a $\mathrm{P} \leq 0.05$ with respect to corresponding normally fed group, $\mathrm{b}$ $\mathrm{P} \leq 0.05$ with respect to corresponding cisplatin treated group, $\mathrm{c} \mathrm{P} \leq 0.05$ with respect to corresponding control group $(n=8)$. 


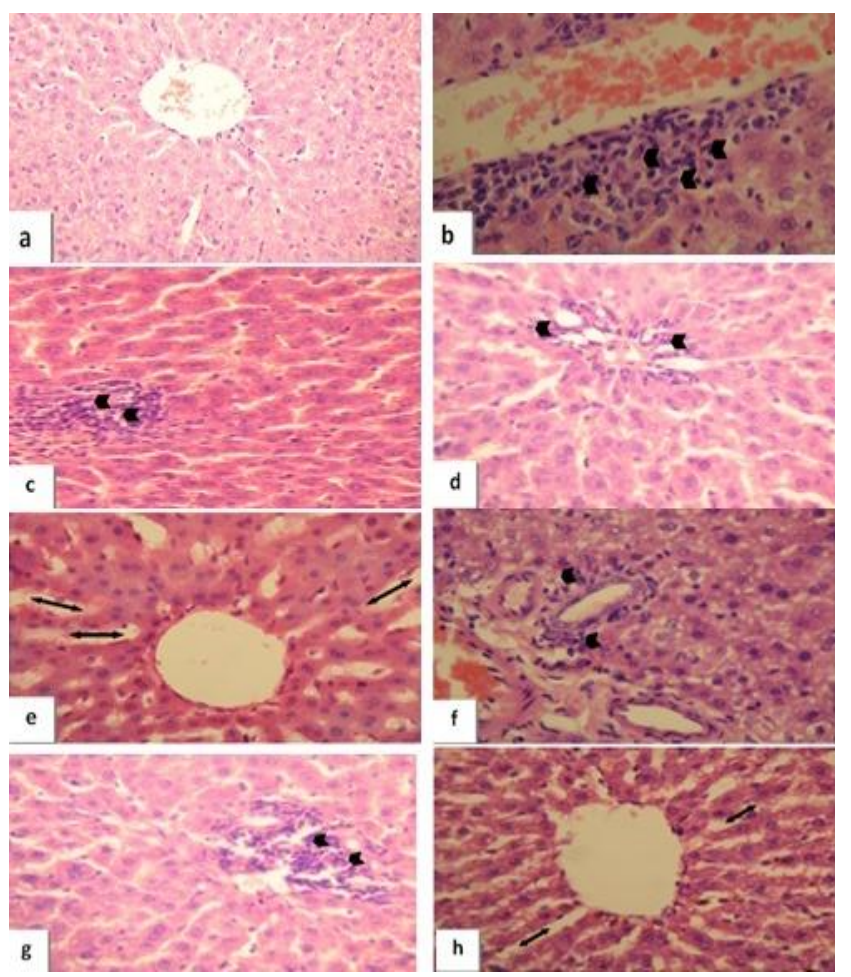

Figure 8: Photomicrographs represent changes in the liver of cisplatin induced hepatotoxicity in the NF set. (a) Control, (b) Cisplatin, (c) Silymarin curative, (d) L-arginine curative, (e) Silymarin and L-arginine curative , (f) Silymarin protective, (g) L-arginine protective, (h) Silymarin and L-arginine protective. Histological examination using $H \& E$ staining of the liver showed significant decrease in the histo-pathological alteration in comparison to cisplatin treated group (head arrow for and infiltration and double head arrow for vasodilatation) $(\mathrm{X} 400)(\mathrm{n}=8)$.
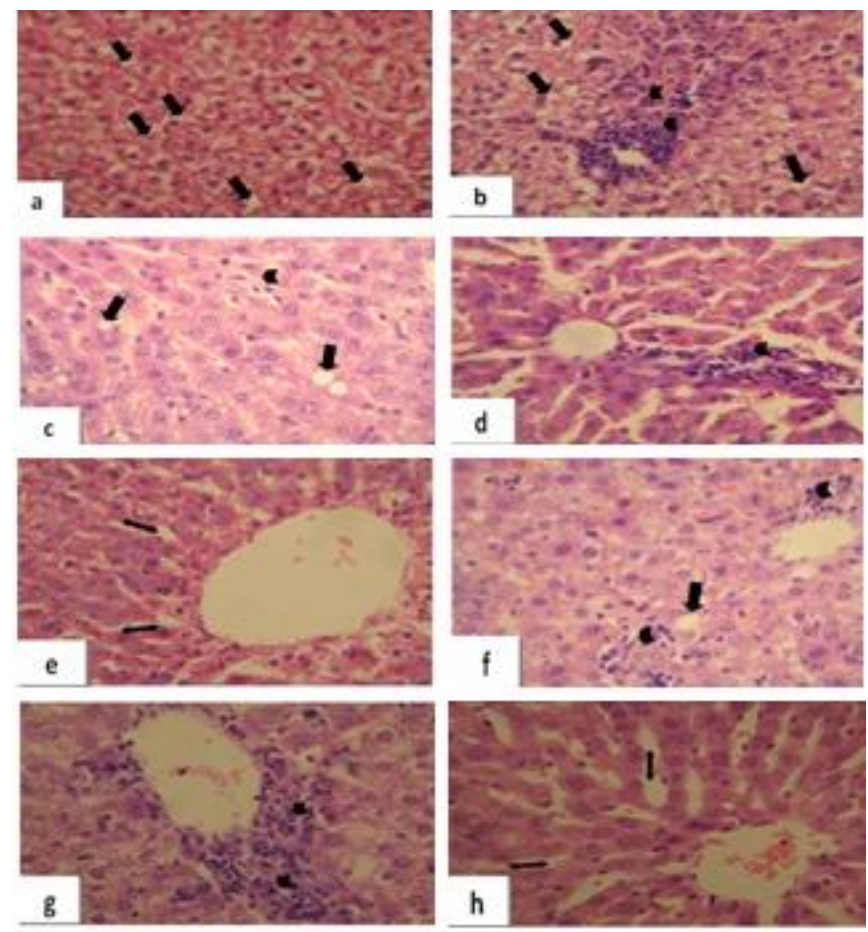

Figure 9: Photomicrographs represent changes in the liver of cisplatin induced hepatotoxicity in the PM set. (a) Control, (b) Cisplatin, (c) Silymarin curative, (d) L-arginine curative, (e) Silymarin and L-arginine curative , (f) Silymarin protective, (g) L-arginine protective, (h) Silymarin and L-arginine protective. Histological examination using $\mathrm{H} \& \mathrm{E}$ staining of the liver showed significant decrease in the histo-pathological alteration in 
comparison to cisplatin treated group (head arrow for and infiltration, double head arrow for vasodilatation and arrow for fatty changes) (X400) $(n=8)$.

Table 1. Effect of administration of silymarin (100mg/kg), l-arginine (200mg/kg)and their combination for 5 days on body weight of cisplatin-induced liver toxicity in normally fed and in protein malnourished rats. Body weight of rats were measured done on day 5 after the induction of liver toxicity expressed as mean \pm S.E.M. All data were analyzed using ANOVA followed by Bonferroni post hock test. a $\mathrm{P} \leq 0.05$ with respect to corresponding normally fed group, $\mathrm{b} \mathrm{P} \leq 0.05$ with respect to corresponding cisplatin treated group, $\mathrm{c} P \leq 0.05$ with respect to corresponding control group.

\begin{tabular}{|l|c|c|}
\hline \multicolumn{2}{|c|}{ body weight } \\
\hline \multicolumn{1}{|c|}{ Groups } & NF & PM \\
\hline Control & $110.5 \pm 2.42^{\mathrm{b}}$ & $97.25 \pm 3.45^{\mathrm{ab}}$ \\
\hline Cisplatin & $103.2 \pm 4.75^{\mathrm{C}}$ & $89.85 \pm 3.58^{\mathrm{aC}}$ \\
\hline Silymarin curative & $112.04 \pm 3.96^{\mathrm{b}}$ & $95.8 \pm 3.83^{\mathrm{ab}}$ \\
\hline L-arginine curative & $108.05 \pm 4.73^{\mathrm{b}}$ & $95.44 \pm 4.64^{\mathrm{ab}}$ \\
\hline L-arginine+ Silymarin curative & $111.35 \pm 3.67^{\mathrm{b}}$ & $97.08 \pm 3.45^{\mathrm{ab}}$ \\
\hline Sly protective & $112 \pm 4.34^{\mathrm{b}}$ & $99.2 \pm 4.94^{\mathrm{ab}}$ \\
\hline L-arginine protective & $112.33 \pm 3.55^{\mathrm{b}}$ & $100.25 \pm 3.52^{\mathrm{ab}}$ \\
\hline L-arginine+ Silymarin protective & $110.7 \pm 4.25^{\mathrm{b}}$ & $102.65 \pm 4.44^{\mathrm{ab}}$ \\
\hline
\end{tabular}

Table 2. Effect of administration of silymarin $(100 \mathrm{mg} / \mathrm{kg}), 1-\operatorname{arginine}(200 \mathrm{mg} / \mathrm{kg})$ and their combination for 5 days on liver ratio of cisplatin-induced liver toxicity in normally fed and in protein malnourished rats. Liver ratio of rats were measured and expressed as mean \pm S.E.M. All data were analyzed using ANOVA followed by Bonferroni post hock test. a $\mathrm{P} \leq 0.05$ with respect to corresponding normally fed group, $\mathrm{b} \mathrm{P} \leq 0.05$ with respect to corresponding cisplatin treated group, $\mathrm{c} P \leq 0.05$ with respect to corresponding control group.

\begin{tabular}{|l|c|c|}
\hline \multicolumn{2}{|c|}{ liver ratio } & PF \\
\hline Groups & NF & $1.75 \pm 0.05^{\mathrm{ab}}$ \\
\hline Control & $4.03 \pm 0.13^{\mathrm{b}}$ & $3.51 \pm 0.05^{\mathrm{ac}}$ \\
\hline Cisplatin & $6.37 \pm 0.25^{\mathrm{c}}$ & $2.94 \pm 0.10^{\mathrm{ab}}$ \\
\hline Silymarin curative & $4.12 \pm 0.31^{\mathrm{b}}$ & $2.05 \pm 0.10^{\mathrm{ab}}$ \\
\hline L-arginine curative & $3.9 \pm 0.2^{\mathrm{b}}$ & $2.10 \pm 0.35^{\mathrm{ab}}$ \\
\hline L-arginine+ Silymarin curative & $3.5 \pm 0.05^{\mathrm{b}}$ & $2.28 \pm 0.14^{\mathrm{ab}}$ \\
\hline Silymarin protective & $4.05 \pm 0.75^{\mathrm{b}}$ & $2.20 \pm 0.08^{\mathrm{ab}}$ \\
\hline L-arginine protective & $4.05 \pm 0.15^{\mathrm{b}}$ & $1.96 \pm 0.09^{\mathrm{ab}}$ \\
\hline L-arginine+ Silymarin protective & $4.11 \pm 0.52^{\mathrm{b}}$ & \\
\hline
\end{tabular}

\section{Conclusions}

We concluded that CDDP elicited harmful hepatotoxic effects may cause severe damage to the plasma membrane, mitochondria and other organelles by suppressing the antioxidant defense mechanism. These effects were potentiated by PM; however, they were improved by 1-arginine and Sly. Thus, the results of the present study support the hypothesis that treatment and pre-treatment with 1-arginine, Sly and their combination is effective in maximizing the clinical use of CDDP in the treatment of various malignancies, by minimizing its hepatotoxicity. Current data propose 1-arginine as a potential inhibitor of CDDP-induced hepatotoxicity.

\section{References}

[1]. Y Horie, R Wolf, J Russell, T P Shanley, D N Granger Role of Kupffer cells in gut ischemia/reperfusion-induced hepatic microvascular dysfunction in mice. Hepatology 26: (1997) 1499-1505.

[2]. A Wolf, C F Trendelenburg, C Diez-Fernandez, P Prieto, S Houy, et al. Cyclosporine A-induced oxidative stress in rat hepatocytes. J Pharmacol Exp Ther 280: (1997) 1328-1334.

[3]. D G Deavall, E A Martin, J M Horner, R Roberts Drug-induced oxidative stress and toxicity. J Toxicol 2012: (2012) 645460.

[4]. S Y Park, Y J Kim, S Y Lee, J G Lee, H R Hwang, et al. Vitamin-Mineral Supplement Use Patterns in Elderly Koreans: Data from the 2007-2008 Korean National Health and Nutrition Examination Survey. Korean J Fam Med 37: (2016) 123-129.

[5]. S Gopalan, S Saran, R Sengupta Practicalities of nutrition support in chronic liver disease. Curr Opin Clin Nutr Metab Care 3: (2000) 227-229.

[6]. F Bonatto, M Polydoro, M E Andrades, M L da Frota Junior, F Dal-Pizzol, et al. Effect of protein malnutrition on redox state of the hippocampus of rat. Brain Res 1042: (2005) 17-22.

[7]. $\quad$ M H Golden, D Ramdath Free radicals in the pathogenesis of kwashiorkor. Proc Nutr Soc 46: (1987) 53-68.

[8]. Y Lu, A I Cederbaum Cisplatin-induced hepatotoxicity is enhanced by elevated expression of cytochrome P450 2E1. Toxicol Sci 89: (2006) 515-523.

[9]. S Iseri, F Ercan, N Gedik, M Yuksel, I Alican Simvastatin attenuates cisplatin-induced kidney and liver damage in rats. Toxicology 230: (2007) 256-264.

[10]. A S Planting, G Catimel, P H de Mulder, A de Graeff, F Hoppener, et al. Randomized study of a short course of weekly cisplatin with or without amifostine in advanced head and neck cancer. EORTC Head and Neck Cooperative Group. Ann Oncol 10: (1999) 693-700.

[11]. P J Loehrer, Sr., R Gonin, C R Nichols, T Weathers, L H Einhorn Vinblastine plus ifosfamide plus cisplatin as initial salvage therapy in recurrent germ cell tumor. J Clin Oncol 16: (1998) 2500-2504. 
[12]. K Noda, Y Nishiwaki, M Kawahara, S Negoro, T Sugiura, et al. Irinotecan plus cisplatin compared with etoposide plus cisplatin for extensive small-cell lung cancer. N Engl J Med 346: (2002) 85-91.

[13]. U Gatzemeier, J von Pawel, M Gottfried, G P ten Velde, K Mattson, et al. Phase III comparative study of high-dose cisplatin versus a combination of paclitaxel and cisplatin in patients with advanced non-small-cell lung cancer. J Clin Oncol 18: (2000) 3390-3399.

[14]. P Hoskins, E Eisenhauer, I Vergote, J Dubuc-Lissoir, B Fisher, et al. Phase II feasibility study of sequential couplets of Cisplatin/Topotecan followed by paclitaxel/cisplatin as primary treatment for advanced epithelial ovarian cancer: a National Cancer Institute of Canada Clinical Trials Group Study. J Clin Oncol 18: (2000) 4038-4044.

[15]. M Verschraagen, E Boven, R Ruijter, K van der Born, J Berkhof, et al. Pharmacokinetics and preliminary clinical data of the novel chemoprotectant BNP7787 and cisplatin and their metabolites. Clin Pharmacol Ther 74: (2003) 157-169.

[16]. X Yao, K Panichpisal, N Kurtzman, K Nugent Cisplatin nephrotoxicity: a review. Am J Med Sci 334: (2007) 115-124.

[17]. G Ramesh, W B Reeves TNF-alpha mediates chemokine and cytokine expression and renal injury in cisplatin nephrotoxicity. J Clin Invest 110: (2002) 835-842.

[18]. G Nowak Protein kinase C-alpha and ERK1/2 mediate mitochondrial dysfunction, decreases in active Na+ transport, and cisplatininduced apoptosis in renal cells. J Biol Chem 277: (2002) 43377-43388.

[19]. T Xiao, S Choudhary, W Zhang, N H Ansari, A Salahudeen Possible involvement of oxidative stress in cisplatin-induced apoptosis in LLC-PK1 cells. J Toxicol Environ Health A 66: (2003) 469-479.

[20]. R Pratibha, R Sameer, P V Rataboli, D A Bhiwgade, C Y Dhume Enzymatic studies of cisplatin induced oxidative stress in hepatic tissue of rats. Eur J Pharmacol 532: (2006) 290-293.

[21]. M Mansour, M H Daba, A Gado, A Al-Rikabi, A Al-Majed Protective effect of L-arginine against nephrotoxicity induced by cyclosporine in normal rats. Pharmacol Res 45: (2002) 441-446.

[22]. M Iraz, E Ozerol, M Gulec, S Tasdemir, N Idiz, et al. Protective effect of caffeic acid phenethyl ester (CAPE) administration on cisplatin-induced oxidative damage to liver in rat. Cell Biochem Funct 24: (2006) 357-361.

[23]. P Ferenci, B Dragosics, H Dittrich, H Frank, L Benda, et al. Randomized controlled trial of silymarin treatment in patients with cirrhosis of the liver. J Hepatol 9: (1989) 105-113.

[24]. M E Horvath, R Gonzalez-Cabello, A Blazovics, M van der Looij, I Barta, et al. Effect of silibinin and vitamin E on restoration of cellular immune response after partial hepatectomy. J Ethnopharmacol 77: (2001) 227-232.

[25]. J Feher, G Lengyel Silymarin in the prevention and treatment of liver diseases and primary liver cancer. Curr Pharm Biotechnol 13 : (2012) 210-217.

[26]. E A Saad Curative and protective effects of L-arginine on carbon tetrachloride-induced hepatotoxicity in mice. Biochem Biophys Res Commun 423: (2012) 147-151.

[27]. G Wu, L A Jaeger, F W Bazer, J M Rhoads Arginine deficiency in preterm infants: biochemical mechanisms and nutritional implications. J Nutr Biochem 15: (2004) 442-451.

[28]. M S Bamji, D Sharada Hepatic glutathione reductase and riboflavin concentrations in experimental deficiency of thiamin and riboflavin in rats. J Nutr 102: (1972) 443-447.

[29]. J C Edozien, M A Rahim-Khan Anaemia in protein malnutrition. Clin Sci 34: (1968) 315-326

[30]. Y C Yadav Hepatoprotective effect of Ficusreligiosa latex on cisplatin induced liver injury in Wistar rats Revista Brasileira de Farmacognosia: (2015) 278-283.

[31]. F A Crocenzi, E J Sanchez Pozzi, J M Pellegrino, E A Rodriguez Garay, A D Mottino, et al. Preventive effect of silymarin against taurolithocholate-induced cholestasis in the rat. Biochem Pharmacol 66: (2003) 355-364.

[32]. S Reitman, S Frankel A colorimetric method for the determination of serum glutamic oxalacetic and glutamic pyruvic transaminases. Am J Clin Pathol 28: (1957) 56-63.

[33]. T V Feichtmeir, H T Wrenn The quantitation of albumin based on its dyebinding capacity. Am J Clin Pathol 26: (1956) 960-968

[34]. H Ohkawa, N Ohishi, K Yagi Assay for lipid peroxides in animal tissues by thiobarbituric acid reaction. Anal Biochem 95: (1979) 351-358.

[35]. G Lippi Interference studies: focus on blood cell lysates preparation and testing. Clin Lab 58: (2012) 351-355.

[36]. M Nishikimi, N Appaji, K Yagi The occurrence of superoxide anion in the reaction of reduced phenazinemethosulfate and molecular oxygen. . BiochemBiophys Res Commun 2: (1972) 849-854.

[37]. E Beutler, O Duron, B M Kelly Improved method for the determination of blood glutathione. J Lab Clin Med 61: (1963) 882-888.

[38]. R A B Drury, E A Wallington Carleton's histological technique. 4th Edition, Oxford University Press, Oxford,New York, Tronto: (1980).

[39]. N L Crogan, A Pasvogel The influence of protein-calorie malnutrition on quality of life in nursing homes. J Gerontol A Biol Sci Med Sci 58: (2003) 159-164.

[40]. G T Keusch The history of nutrition: malnutrition, infection and immunity. J Nutr 133: (2003) 336S-340S.

[41]. M Oumi, M Miyoshi, T Yamamoto The ultrastructure of skeletal and smooth muscle in experimental protein malnutrition in rats fed a low protein diet. Arch Histol Cytol 63: (2002) 451-457.

[42]. E Ezzeldin, Y Raslan, T El-Nahhas, A Y Asiri Possible Protective Effects of Garlic, Ginkobiloba and Silymarin on Cisplatin Hepatotoxicity in Protein-Malnourished Rats British Journal of Medicine \& Medical Research 34: (2014) 5398-5414.

[43]. F Bozzetti Nutrition support in patients with cancer. In: Payne-James J, et al. ed. Artificial Nutrition Support in Clinical Practice, 2nd edn. London. GMM: (2001).

[44]. R Fock, M Rogero, P Borelli Protein-energy malnutrition alters the C3 complement factor in response to lipopolysaccharide in a murine model. J Brazilian Soc Food Nutr (2009) 131-142.

[45]. K C Obimba Utilization of high quality weaning formulae as dietary therapies of protein energy malnutrition. Int J Biochem Biotech 9: (2012) 230-238.

[46]. S Wati, S M Rawlinson, R A Ivanov, L Dorstyn, M R Beard, et al. Tumour necrosis factor alpha (TNF-alpha) stimulation of cells with established dengue virus type 2 infection induces cell death that is accompanied by a reduced ability of TNF-alpha to activate nuclear factor kappaB and reduced sphingosine kinase-1 activity. J Gen Virol 92: (2011) 807-818.

[47]. F Akinola, O Oguntibeju, O Alabi Effects of severe malnutrition on oxidative stress in Wister rats. Sci Res Essays 10: (2010) 11451149 .

[48]. M Bosnak, S Kelekci, S Yel, Y Kocyigit, V Sen, et al. Oxidative Stress in Marasmic Children: Relationships with Leptin. Eur J Gen Med 1: (2010) 18.

[49]. F Cavalli, L Tschopp, R W Sonntag, A Zimmermann A case of liver toxicity following cis-dichlorodiammineplatinum(II) treatment. Cancer Treat Rep 62: (1978) 2125-2126.

[50]. R J Cersosimo Hepatotoxicity associated with cisplatin chemotherapy. Ann Pharmacother 27: (1993) 438-441. 
[51]. A Naqshbandi, W Khan, S Rizwan, F Khan Studies on the protective effect of flaxseed oil on cisplatin-induced hepatotoxicity. Hum Exp Toxicol 31: (2012) 364-375.

[52]. T Dubskaia, T V Vetoshkina, V E Gol'dberg [The mechanisms of the hepatotoxicity of complex platinum compounds]. Eksp Klin Farmakol 57: (1994) 38-41.

[53]. S Saad, T Najjar, M Alashari Role of nonselective adenosine receptor blockade and phosphodiesterase inhibition in cisplatininduced nephrogonadal toxicity in rats. . Clin Exp Pharmacol Physiol 31: (2004) 862-867.

[54]. G Kadikoylu, Z Bolaman, S Demir, M Balkaya, N Akalin, et al. The effects of desferrioxamine on cisplatin-induced lipid peroxidation and the activities of antioxidant enzymes in rat kidneys. Hum Exp Toxicol 23: (2004) 29-34.

[55]. L Klukowska, A Nadulska, S Dyba The influence of cisplatinum and goserelinum on the magnesium and calcium level in rat serum. Ann Univ Mariae Curie Sklodowska Med 56: (2001) 483-486.

[56]. P Jordan, M Carmo-Fonseca Molecular mechanisms involved in cisplatin cytotoxicity. Cell Mol Life Sci 57: (2000) 1229-1235.

[57]. S A Khan, S Priyamvada, W Khan, S Khan, N Farooq, et al. Studies on the protective effect of green tea against cisplatin induced nephrotoxicity. Pharmacol Res 60: (2009) 382-391.

[58]. N Fatima, K Niaz, Z Maseeh Uz, S Kamal, A Hameed Nephrotoxicity of CDDP assessed estimating glomerular filtration rate with 99mTc-DTPA plasma sample method. J Coll Physicians Surg Pak 20: (2010) 98-101.

[59]. M B Witte, A Barbul Arginine physiology and its implication for wound healing. Wound Repair Regen 11: (2003) 419-423.

[60]. J K Stechmiller, B Childress, L Cowan Arginine supplementation and wound healing. Nutr Clin Pract 20: (2005) 52-61.

[61]. J A Kennedy, S J Kirk, D C McCrory, M I Halliday, G R Barclay, et al. Modulation of immune function and weight loss by Larginine in obstructive jaundice in the rat. Br J Surg 81: (1994) 1199-1201.

[62]. E A Saad Kidney response to L-arginine treatment of carbon tetrachloride-induced hepatic injury in mice. Natural Science 5: (2013) $1-6$.

[63]. H Tkachenko, N Kurhalyuk Role of L-arginine Against Lead Toxicity in Liver of Rats with Different Resistance to Hypoxia Pol J Environ Stud 20: (2011) 1319-1325.

[64]. C Bauer, F Walcher, U Kalweit, R Larsen, I Marzi Role of nitric oxide in the regulation of the hepatic microcirculation in vivo. J Hepatol 27: (1997) 1089-1095.

[65]. M Suematsu, T Tamatani, F A Delano, M Miyasaka, M Forrest, et al. Microvascular oxidative stress preceding leukocyte activation elicited by in vivo nitric oxide suppression. Am J Physiol 266: (1994) H2410-2415.

[66]. R P Singh, R Agarwal Flavonoid antioxidant silymarin and skin cancer. Antioxid Redox Signal 4: (2002) 655-663.

[67]. L A Ramadan, H M Roushdy, G M Abu Senna, N E Amin, O A El-Deshw Radioprotective effect of silymarin against radiation induced hepatotoxicity. Pharmacol Res 45: (2002) 447-454.

[68]. M O Taha, M J Simoes, M A Haddad, R C Capelato, N Budny, et al. 1-Arginine supplementation protects against hepatic ischemiareperfusion lesions in rabbits. Transplant Proc 41: (2009) 816-819.

[69]. A Nahavandi, A R Dehpour, A R Mani, H Homayounfar, A Abdoli, et al. The role of nitric oxide in bradycardia of rats with obstructive cholestasis. Eur J Pharmacol 411: (2001) 135-141. 